\title{
ANÁLISE DA DIVERSIDADE GENÉTICA POR AFLP E IDENTIFICAÇÃO DE MARCADORES ASSOCIADOS À RESISTÊNCIA A DOENÇAS EM VIDEIRA ${ }^{1}$
}

\author{
PAULO RICARDO DIAS DE OLIVEIRA², DANIELLE CAMARGO SCOTTON ${ }^{3}$, DEBORAH SANAE NISHIMURA ${ }^{3}$, \\ ANTONIO FIGUEIRA ${ }^{4}$
}

\begin{abstract}
RESUMO - Com objetivo de estudar diversidade genética e identificar marcadores associados à resistência ao míldio (Plasmopara viticola) e ao oídio (Uncinula necator), foram analisadas as cultivares de videira A 1976, CG 87746, CNPUV 154-27, Crimson Seedless, Gota de Ouro, Itália, Seyve Villard 12327 e Seyve Villard 12375. As análises de polimorfismo de comprimento de fragmento amplificado (AFLP) seguiram as etapas de digestão, ligação, pré-amplificação e amplificação. Efetuou-se a separação dos fragmentos amplificados em gel de 7\% de poliacrilamida desnaturante (uréia $7 \mathrm{M}$ ) e coloração com nitrato de prata. A similaridade foi estimada com base no coeficiente de Jaccard, e a agregação, por UPGMA. Foi gerada uma matriz de similaridade com bom ajustamento da agregação $(r=0,84)$. Os agrupamentos obtidos corresponderam à origem e classificação botânica das cultivares. Foram identificadas 15 marcas dissimilares associadas à resistência, sendo oito para míldio e sete para oídio.
\end{abstract}

Termos para indexação: videira, marcadores AFLP, resistência a doenças, míldio, oídio.

\section{GENETIC DIVERSITY AND IDENTIFICATION OF AFLP MARKERS ASSOCIATED WITH DISEASES RESISTANCE IN GRAPEVINE}

\begin{abstract}
The grapevine cultivars A 1976, CG 87746, CNPUV 154-27, Crimson Seedless, Gota de Ouro, Itália, Seyve Villard 12327 and Seyve Villard 12375 were analyzed to establish the genetic relationship and to identify markers associated with resistance to downy mildew (Plasmopara viticola) and powdery mildew (Uncinula necator). The amplified fragment lenght polymorphism (AFLP) analysis comprise the steps of digestion, ligation, preamplification and amplification. The amplified fragments were separeted on a 7\% denaturing polyacrylamide gel ( $7 \mathrm{M}$ urea) and silver stained. The similarity was estimated using Jaccard's coefficient and the clustering was estimated by UPGMA. A similarity matrix was generated with a good fit for aggregation $(\mathrm{r}=0,84)$. The clusters corresponded to origin and botany classification of the cultivars. Fifteen markers were associated with resistance, eight for downy mildew and seven for powdery mildew.
\end{abstract}

Index terms: grapevine, AFLP markers, disease resistance, downy mildew, powdery mildew.

\section{INTRODUÇÃO}

Os marcadores moleculares são entidades herdáveis passíveis de utilização na seleção de plantas. Dentre as aplicações dos marcadores moleculares no melhoramento vegetal, está a seleção assistida de características de importância agronômica, a qual se fundamenta no mapeamento e associação de marcadores a genes que controlam essas características de interesse. Por conseguinte, o sucesso da seleção assistida por marcadores (MAS) depende do mapeamento preciso de regiões do genoma associadas a estas características (Milach, 1998).

A MAS tem potencial para aumentar a eficiência de seleção por permitir avaliação e seleção antecipada e por reduzir o tamanho da população de plantas usada durante a seleção. Segundo Staub et al. (1996), possivelmente, as melhores oportunidades de aplicação com sucesso da MAS estejam no melhoramento para resistência às doenças, especialmente quando diversos genes controlam a resistência, envolvendo interações complexas, e onde a piramidização de genes é desejável. Para culturas perenes, é uma metodologia extremamente atraente, tendo em vista o tempo necessário para completar uma geração ou ciclo de melhoramento de tais espécies. A perspectiva é tornar mais eficiente a seleção pelo aumento de ganho genético por unidade de tempo (Ferreira \& Grattapaglia, 1998).

A videira está sujeita à ocorrência de diversas doenças fúngicas, as quais reduzem a quantidade e a qualidade da fruta produzida, podendo, em determinadas situações, inviabilizar a cultura. O míldio (Plasmopara viticola) e o oídio (Uncinula necator) estão entre as principais doenças fúngicas que atacam a videira no Brasil. O míldio pode causar sérios prejuízos nas épocas do ano com precipitação pluviométrica elevada. No caso do oídio, a incidência é mais importante nas áreas tropicais, durante o período seco.

As diversas espécies do gênero Vitis não reagem a patógenos de forma similar. Em geral, as cultivares de $V$. vinifera são bastante suscetíveis a patógenos e pragas. Por outro lado, as videiras americanas
(V. labrusca) e híbridas e outras espécies de Vitis são tolerantes ou mesmo resistentes a patógenos. Nesta linha, Reisch \& Pratt (1996) citam $V$. aestivalis, $V$. cinerea e $V$. labrusca, como fontes de resistência ao míldio, e $V$. cinerea e $V$.rupestris, como fontes de resistência ao oídio.

Buscando explorar a variabilidade genética, os programas de melhoramento de videira têm lançado cultivares que, além dos atributos de produtividade e qualidade, agreguem a resistência a doenças, em vista do apelo crescente em favor da saúde de produtores e consumidores e da sustentabilidade ambiental e econômica das atividades agrícolas.

Os marcadores gerados pela análise de polimorfismos de comprimento de fragmento amplificado (AFLP), descrita por Vos et al. (1995), associam os polimorfismos gerados por enzimas de restrição com a capacidade de detecção da técnica de PCR. O DNA total da planta é clivado por enzimas de restrição, originando um número extremamente elevado de fragmentos que, em função da concentração, não são detectados em eletroforese. Pequenas seqüências de DNA (adaptadores) são acopladas às extremidades desses fragmentos de restrição, as quais se anelarão com primers específicos, durante a PCR (pré-amplificação e amplificação seletiva). Os fragmentos gerados são então separados por eletroforese em gel de poliacrilamida desnaturante.

A técnica de AFLP apresenta vantagens comparativas, tais como detecção de maior número de lócus, cobertura ampla do genoma e baixo custo (Lopes et al., 2002). A estratégia de exploração conjugada dos marcadores AFLP e SSR, predominante na literatura, estabelece condições para a confecção de mapas genéticos saturados e cria oportunidades para ação integrada com outras equipes envolvidas com a mesma problemática em videira.

Pauquet et al. (2001) construíram, com marcadores AFLP, mapa genético ao redor do gene Run 1 (resistência ao oídio). Três marcadores foram selecionados para uso na seleção assistida (Emhb1, Embd4 e Emfd3). Em outro mapa genético, Dalbó et al. (2001), utilizando marcadores RAPD e AFLP, encontraram QTL que explicava $41 \%$ da

\footnotetext{
${ }^{1}$ (Trabalho 077/2005). Recebido: 06/05/2005. Aceito para publicação: 06/10/2005.

${ }^{2}$ Eng.Agr., Dr., Pesquisador, Embrapa Uva e Vinho. C.P. 130. 95700-000 Bento Gonçalves-RS. paulo@cnpuv.embrapa.br.

${ }^{3}$ Bióloga, Mestranda, Centro de Energia Nuclear na Agricultura, Universidade de São Paulo. Piracicaba-SP.

${ }^{4}$ Eng.Agr., PhD, Prof. Associado, Centro de Energia Nucear na Agricultura, Universidade de São Paulo. Piracicaba-SP.
} 
variação observada e localizaram dois marcadores associados com a resistência ao oídio.

Os marcadores AFLP também têm apresentado bons resultados para outras aplicações, como caracterização da variação somaclonal decorrente da cultura de tecidos e órgãos vegetais (Popescu et al., 2002), identificação de mutantes (Scott et al., 2000) e análise de quimeras (Franks et al., 2002), ratificando a utilidade dessa ferramenta de análise genética.

O objetivo deste trabalho foi estudar, mediante a aplicação da técnica de AFLP, a diversidade genética de cultivares de videira e identificar marcadores associados à resistência ao míldio e ao oídio.

\section{MATERIAL E MÉTODOS}

Foram estudadas as cultivares A 1976, CG 87746, CNPUV 15427, Crimson Seedless, Gota de Ouro, Itália, Seyve Villard 12327 e Seyve Villard 12375. Este conjunto de genótipos apresenta diferentes níveis de suscetibilidade a míldio e oídio e tem sido amplamente utilizado no programa de melhoramento genético de videira da Embrapa Uva e Vinho com o objetivo de desenvolver novas cultivares de uvas apirênicas (sem sementes) (Tabela 1).

TABELA 1 - Cultivares de videira analisadas: origem e reação ao míldio e ao oídio.

\begin{tabular}{cccc}
\hline \multirow{2}{*}{ Cultivares } & Classificação & \multicolumn{2}{c}{ Suscetibilidade $^{2}$} \\
\cline { 3 - 4 } & botânica & Míldio & Oídio $^{1}$ \\
\hline A 1976 & Híbrido complexo & $\mathrm{R}$ & $\mathrm{S}$ \\
CG 87746 & Vitis vinifera $^{1}$ & $\mathrm{~S}$ & $\mathrm{~S}$ \\
CNPUV 154-27 & Híbrido complexo & $\mathrm{R}$ & $\mathrm{S}$ \\
Crimson Seedless & Vitis vinifera $^{1}$ & $\mathrm{~S}$ & $\mathrm{~S}$ \\
Gota de Ouro & Vitis labrusca & $\mathrm{R}$ & $\mathrm{S}$ \\
Itália & Vitis vinifera $^{1}$ & $\mathrm{~S}$ & $\mathrm{~S}$ \\
Seyve Villard 12327 & Híbrido complexo & $\mathrm{R}$ & $\mathrm{S}$ \\
Seyve Villard 12375 & Híbrido complexo $^{1}$ & $\mathrm{R}$ & $\mathrm{R}$ \\
\hline
\end{tabular}

${ }^{1}$ Ascendência: $V$. labrusca, $V$. rupestris, $V$. aestivalis, $V$. cinerea $\mathrm{e} V$. vinifera.

${ }^{2} \mathrm{R}=$ resistente, notas 1 ou 3 , e $\mathrm{S}=$ suscetível, notas 7 ou 9 .

Fonte: Camargo, U.A. (Com. pessoal). BAG Uva, Embrapa Uva e Vinho, B. Gonçalves-RS.

Foi utilizado o AFLP Analysis System II/ AFLP Small Genome Primer Kit (Invitrogen Corporation). Compunham o kit oito primers específicos para a região clivada pela enzima Mse I (finais CAA, CAC, CAG, CAT, CTA, CTC, CTG e CTT) e oito para a região clivada pela enzima EcoR I (finais AA, AC, AG, AT, TA, TC, TG, TT), possibilitando um total de 64 combinações de pares de primers.

O DNA proveniente de amostras, compostas de seis a oito folhas jovens, de cada um dos genótipos, foi extraído de acordo com o protocolo proposto de Lodhi et al. (1994), no Laboratório de Biologia Molecular, da Embrapa Uva e Vinho, em Bento Gonçalves-RS, e enviado para o Laboratório de Melhoramento de Plantas - LAMP, Centro de Energia Nuclear na Agricultura - CENA, Universidade de São Paulo USP, em Piracicaba-SP, onde o trabalho foi realizado. Nas análises de AFLP, foram seguidas as seguintes etapas: digestão do DNA com as enzimas EcoR I e Mse I; ligação dos fragmentos de DNA com adaptadores; pré-amplificação e amplificação das amostras com os pares (combinações) de primers. Estes procedimentos foram realizados de acordo com a metodologia recomendada pelo fabricante do kit.

Os fragmentos amplificados foram separados em gel de poliacrilamida desnaturante, aplicado em cuba de eletroforese vertical grande, modelo Hoefer SQ3 Sequencer (Pharmacia Biotech). A coloração dos géis, através da utilização de nitrato de prata, foi feita de acordo com a metodologia apresentada por Creste et al. (2001). Foram realizadas 39 corridas, cada uma delas incluindo quatro ou cinco combinações de primers, chegando a ser executadas até cinco repetições de cada uma das 64 combinações de primers disponíveis.

Efetuou-se uma série de ajustes com a finalidade de melhorar a nitidez e o padrão das bandas produzidas, alterando-se a concentração da acrilamida (de 6 para 7\%), o tempo de corrida (de 120 para 150 minutos) e a potência da fonte (de 50 para $55 \mathrm{~W}$ ). O resultado das análises foi documentado, sendo feita a seleção das melhores combinações de primers, no que se refere à resolução produzida e ao polimorfismo das bandas geradas. Os fragmentos de DNA gerados pelas análises de AFLP foram avaliados mediante inspeção visual dos géis. Foram atribuídos escores, como uma característica binária, por presença (1) ou ausência (0). Os dados obtidos foram analisados empregando o programa NTSYSpc, versão 2.02g (Rohlf, 1997).

A matriz de similaridade foi calculada com base no coeficiente de Jaccard $[G S(i j)=a /(a+b+c)$, onde GS(ij) é a medida da similaridade entre indivíduos i e j; a é o número de bandas polimórficas que são compartilhadas por i e j; b é o número de bandas presentes em i e ausentes em j; e c é o número de bandas presentes em j e ausentes em i]. Os dados gerados foram utilizados na análise de agrupamento pelo método UPGMA. O ajustamento da agregação obtida foi verificado pela comparação da matriz de similaridade genética original com a matriz cofenética dela derivada (correlação cofenética).

\section{RESULTADOS E DISCUSSÃO}

Das amostras analisadas, somente aquelas correspondentes à 'Gota de Ouro' não apresentaram um perfil eletroforético aceitável. Podese supor, neste caso, que a natureza do problema esteja associada à qualidade do DNA extraído, pois, diferentemente das demais, esta cultivar é uma $V$. labrusca pura e, possivelmente, requeira algum ajuste no protocolo de extração. Assim, pelo fato de praticamente na totalidade dos géis terem sido observadas falhas deste genótipo ou terem sido incluídas apenas as restantes sete cultivares, na montagem dos arquivos correspondentes aos escores e nas subseqüentes análises dos dados relativos ao estudo de diversidade genética, optou-se pela não-inclusão dos dados referentes a este material.

Os melhores géis foram obtidos com acrilamida a 7\% e uréia $7 \mathrm{M}$, tempo de corrida de 150 minutos e potência ajustada para $55 \mathrm{~W}$. A análise das imagens digitalizadas dos 31 géis de melhor qualidade possibilitou selecionar, dentre as 64 combinações de primers, as que produziram melhor resolução e polimorfismo de bandas. Conforme é apresentado na Tabela 2, foram localizadas 236 marcas dissimilares como produto da análise dos géis referentes às consideradas 14 melhores combinações de primers.

TABELA 2 - Combinações de primers selecionadas pela definição e polimorfismo.

\begin{tabular}{cccc}
\hline \multirow{2}{*}{$\begin{array}{c}\text { Combinações } \\
\text { de } \text { primers }\end{array}$} & \multicolumn{3}{c}{ Número de bandas (participação relativa em \%) } \\
\cline { 2 - 4 } AA+CAC & $14(40)$ & Similares & Total \\
\hline AA+CTT & $6(32)$ & $13(60)$ & 35 \\
AC+CAC & $19(63)$ & $11(37)$ & 19 \\
AC+CAG & $16(42)$ & $22(58)$ & 30 \\
AC+CAT & $24(51)$ & $23(49)$ & 38 \\
AC+CTT & $22(52)$ & $20(48)$ & 47 \\
AG+CAC & $18(42)$ & $25(58)$ & 43 \\
AG+CAG & $13(36)$ & $23(64)$ & 36 \\
AT+CAC & $21(55)$ & $17(45)$ & 38 \\
TA+CAC & $24(63)$ & $14(37)$ & 38 \\
TA+CAT & $11(44)$ & $14(56)$ & 25 \\
TC+CAC & $20(50)$ & $20(50)$ & 40 \\
TG+CAC & $14(39)$ & $22(61)$ & 36 \\
TG+CAG & $14(37)$ & $24(63)$ & 38 \\
\hline Total & $236(47)$ & $269(53)$ & 505 \\
\hline
\end{tabular}

A Tabela 3 mostra a matriz de similaridade calculada. Os valores cofenéticos derivados da matriz de similaridade são apresentados na Tabela 4. Obteve-se $r=0,84$ para correlação cofenética, o que indica bom ajuste $(0,8<\mathrm{r}<0,9)$ para esta medida de qualidade ou de 


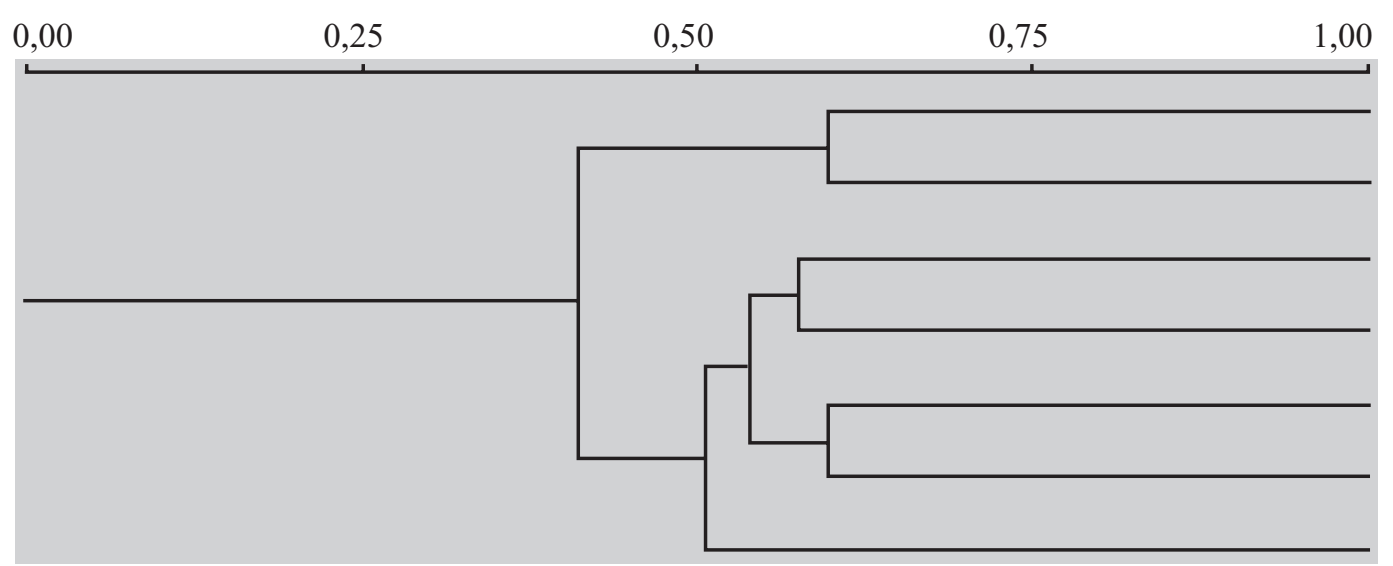

Seyve Villard 12375

Seyve Villard 12327

Crimson Seedless

Itália

CNPUV 154-27

CG 87746

A 1976

FIGURA 1 - Representação do relacionamento genético entre as cultivares baseado nas análises de AFLP.

ajustamento da agregação.

Havia a expectativa de que a genotipagem feita gerasse agrupamentos que correspondessem à origem ou classificação botânica das cultivares em estudo. Como pode ser observado no dendograma obtido (Figura 1), foram agregados os materiais com relacionamento genético mais próximo (Tabela 1). A eficiência na caracterização de recursos genéticos, via aplicação de marcadores AFLP, tem sido atestada em outros trabalhos com videira (Sensi et al., 1996; Cervera et al., 1998; Cervera et al., 2001; Fanizza et al., 2003).

TABELA 3 - Similaridade entre genótipos baseada nas análises de AFLP. \begin{tabular}{cccccccc}
\hline Cvs. & SV & SV & Crimson & Itália & $154-27$ & A 1976 & CG \\
& 12375 & 12327 & & & & & 87746
\end{tabular} SV 12375

SV

12327

Crimson

Itália

$154-27$

A 1976

CG

87746

\section{$0,598 \quad 1$}

\section{0,362}

0,410

0,519

\section{0,294}

0,414

$0,453 \quad 0,382$

1
0,576
0,520
0,466
0,572

1

0,505

0,470

0,564

0,528

$0,598-0,552$

$0,552 \quad 1$

TABELA 4 - Valores cofenéticos derivados da matriz de similaridade.

\begin{tabular}{lccccccc}
\hline \multicolumn{1}{c}{ Cvs. } & SV & SV & Crimson & Itália & $154-27$ & A 1976 & CG \\
& 12375 & 12327 & & & & & 87746 \\
SV & 1 & & & & & & \\
12375 & & & & & & & \\
SV & 0,598 & 1 & & & & & \\
12327 & & & & & & & \\
Crimson & 0,412 & 0,412 & 1 & & & & \\
Itália & 0,412 & 0,412 & 0,576 & 1 & & & \\
$154-27$ & 0,412 & 0,412 & 0,540 & 0,540 & 1 & & \\
A 1976 & 0,412 & 0,412 & 0,506 & 0,506 & 0,506 & 1 & \\
CG & 0,412 & 0,412 & 0,540 & 0,540 & 0,598 & 0,506 & 1 \\
87746 & & & & & & &
\end{tabular}

TABELA 5 - Marcas derivadas de AFLP, relacionadas à reação ao míldio e ao oídio.

\begin{tabular}{|c|c|c|}
\hline \multirow{2}{*}{$\begin{array}{c}\text { Combinações de } \\
\text { primers }\end{array}$} & \multicolumn{2}{|c|}{$\begin{array}{l}\text { Presença de bandas para míldio }(\mathrm{M}) \text { e oídio } \\
\text { (O) e número de pares de base de cada marca }\end{array}$} \\
\hline & Resistência & Suscetibilidade \\
\hline $\mathrm{AA}+\mathrm{CAC}$ & $(\mathrm{M}-370)$ & $(\mathrm{M}-340)$ \\
\hline $\mathrm{AA}+\mathrm{CTT}$ & & $(\mathrm{O}-410)$ \\
\hline $\mathrm{AC}+\mathrm{CAC}$ & $(\mathrm{M}-380)$ & \\
\hline $\mathrm{AC}+\mathrm{CAG}$ & & $(M-460)$ \\
\hline $\mathrm{AC}+\mathrm{CTT}$ & & $(\mathrm{O}-510)$ \\
\hline $\mathrm{AG}+\mathrm{CAC}$ & $(\mathrm{M}-330)(\mathrm{O}-220)$ & \\
\hline $\mathrm{AG}+\mathrm{CAG}$ & $(\mathrm{O}-560)$ & \\
\hline $\mathrm{AT}+\mathrm{CAC}$ & $(\mathrm{M}-350)$ & \\
\hline $\mathrm{TA}+\mathrm{CAC}$ & & $(\mathrm{O}-310)(\mathrm{O}-410)$ \\
\hline $\mathrm{TG}+\mathrm{CAC}$ & $(M-410)$ & $(\mathrm{M}-300)(\mathrm{O}-390)$ \\
\hline
\end{tabular}

Foram ainda identificadas 15 marcas dissimilares para resistência/suscetibilidade, sendo oito para míldio e sete para oídio, coincidentes com a avaliação fenotípica das cultivares em estudo, como apresentado na Tabela 1. As marcas para míldio foram localizadas com os primers $\mathrm{AA}+\mathrm{CAC}$ (duas marcas), $\mathrm{AC}+\mathrm{CAC}, \mathrm{AC}+\mathrm{CAG}, \mathrm{AG}+\mathrm{CAC}$, $\mathrm{AT}+\mathrm{CAC}$ e $\mathrm{TG}+\mathrm{CAC}$ (duas marcas). As marcas para oídio foram localizadas com os primers $\mathrm{AA}+\mathrm{CTT}, \mathrm{AC}+\mathrm{CTT}, \mathrm{AG}+\mathrm{CAC}, \mathrm{AG}+\mathrm{CAG}$, $\mathrm{TA}+\mathrm{CAC}$ (duas marcas) e TG $+\mathrm{CAC}$ (Tabela 5). Para ilustrar, a Figura 2 mostra um gel obtido com a combinação $\mathrm{AG}+\mathrm{CAC}$, onde foram identificadas marcas para míldio e oídio, caracterizadas pela presença de bandas nos materiais resistentes e ausência nos suscetíveis. Os marcadores identificados no trabalho deverão ser futuramente avaliados em bulks contrastantes das populações que segreguem para estas características.

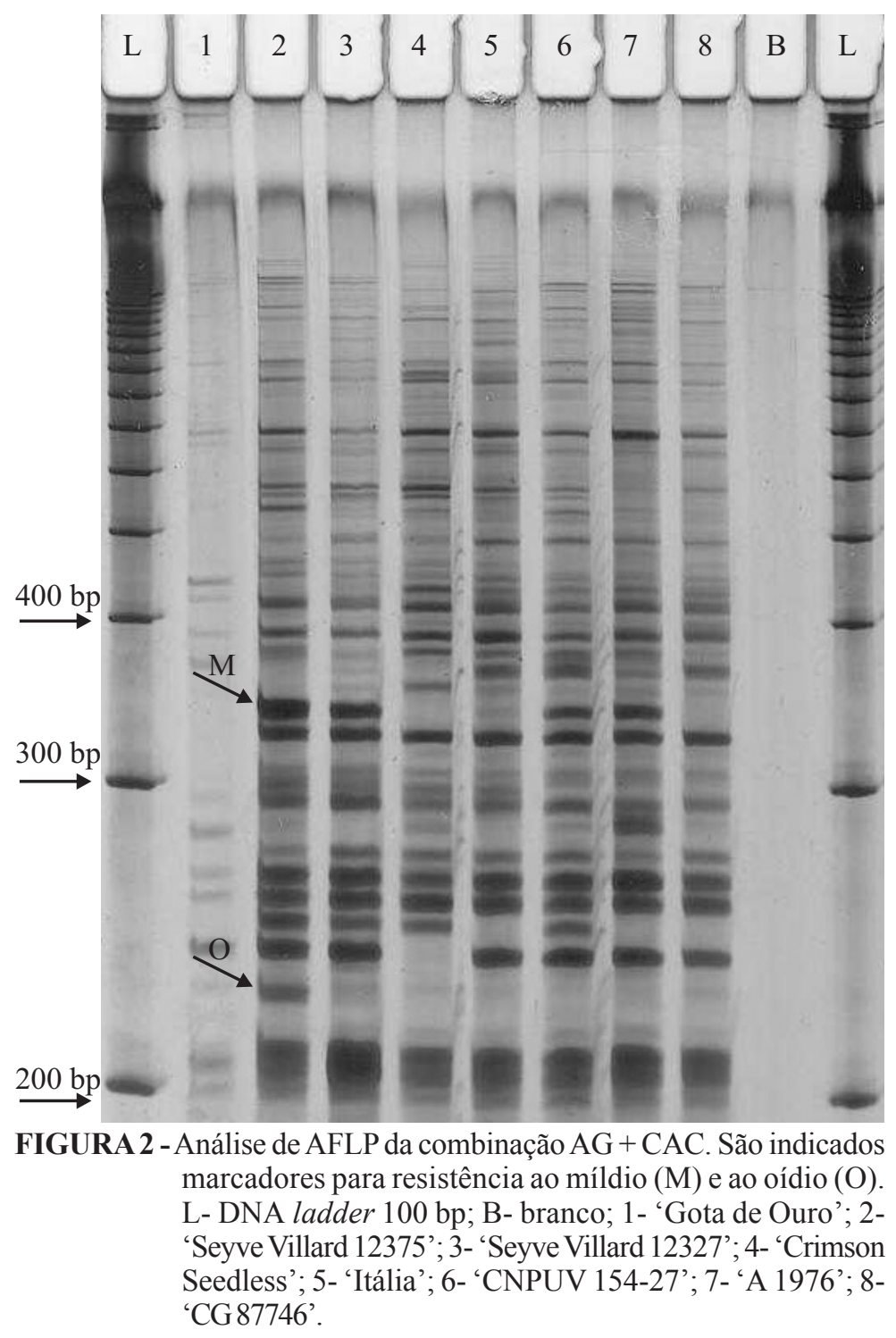




\section{CONCLUSÕES}

1. Os agrupamentos gerados por marcadores AFLP corresponderam à classificação botânica das cultivares.

2. Os marcadores identificados por presença/ausência em cultivares contrastantes para resistência/suscetibilidade ao míldio e ao oídio devem ser futuramente avaliados em bulks contrastantes de populações que segreguem para suscetibilidade a estas doenças.

\section{AGRADECIMENTOS}

Os autores agradecem ao Dr. Luís Fernando Revers, pesquisador da Embrapa Uva e Vinho, pelo preparo das amostras de DNA, e à Dra. Silvana Creste, bolsista da FAPESP, pós-doutoranda do LAMP/CENA/USP, pelo suporte no processamento e na análise dos dados relativos à diversidade genética.

\section{REFERÊNCIAS}

CERVERA, M.T.; CABEZAS, J.A.; SANCHA, J.C.; MARTÍNEZ-TODA, F.; MARTÍNEZ-ZAPATER, J.M. Application of AFLPs to the characterization of grapevine Vitis vinifera L. genetic resources. A case study with accessions from Rioja (Spain). Theoretical and Applied Genetics, Berlin, v.97, n.1/2, p.51-59, 1998.

CERVERA, M.T.; RODRIGUEZ, I.; CABEZAS, J.A.; CHAVES, J.; MARTÍNEZ-ZAPATER, J.M.; CABELLO, F. Morphological and molecular characterization of grapevine accessions known as Albillo. American Journal of Enology and Viticulture, Davis, v.52, n.2,p.127-135, 2001

CRESTE, S.; TULMANN NETO, A.; FIGUEIRA, A. Detection of single sequence repeat polymorphisms in denaturing polyacrilamide sequencing gels by silver staining. Plant Molecular Biology Reporter, Athens, v.19, n.4, p.299-306, 2001.

DALBÓ, M.A.; YE, G. N.; WEEDEN, N.F.; WILCOX, W. F.; REISCH, B. I. Marker-assisted selection for powdery mildew resistance in grapes. Journal of the American Society for Horticultural Science, Mount Vernon, v.126, n.1, p.83-89, 2001.

FANIZZA, G.; CHAABANE, R.; LAMAJ, F.; RICCIARDI, L.; RESTA, P. AFLP analysis of genetic relationships among aromatic grapevines (Vitis vinifera). Theoretical and Applied Genetics, Berlin, v.107, n.6,p.1043-1047, 2003.

FERREIRA, M.E.; GRATTAPAGLIA, D. Introdução ao uso de marcadores moleculares em análise genética. Brasília: EMBRAPACENARGEN, 1998.220p.
FRANKS, T.; BOTTA, R.; THOMAS, M.R. Chimerism in grapevines: implications for cultivar identity, ancestry and genetic improvement. Theoretical and Applied Genetics, Berlin, v.104, n.2/3, p.192-199, 2002.

LODHI, M.A.; YE, G.N.; WEEDEN, N.F.; REISCH, B.I. A simple and efficient method for DNA extraction from grapevine cultivars and Vitis species. Plant Molecular Biology Reporter, Athens, v.12, n.1, p.6-13, 1994.

LOPES, M.S.; LOPES, M.T.G.; FIGUEIRA, A.; CAMARGO, L.E.A.; FUNGARO, M.H.P.; CARNEIRO, M.S.; VIEIRA, M.L.C. Marcadores moleculares dominantes (RAPD e AFLP). Biotecnologia Ciência \& Desenvolvimento, Uberlândia, v.5, n.29, p.56-60, 2002.

MILACH, S.C.K. Mapeamento molecular de características de importância agronômica. In: MILACH, S.C.K. (Ed.). Marcadores moleculares em plantas. Porto Alegre: Universidade Federal do Rio Grande do Sul, 1998. p.67-73.

PAUQUET, J.; BOUQUET, A.; THIS, P.; ADAM-BLONDON, A.F. Establishment of a local map of AFLP markers around the powdery mildew resistance gene Run 1 in grapevine and assessment of their usefulness for marker assisted selection. Theoretical and Applied Genetics, Berlin, v.103, n.8, p.1201-1210, 2001.

POPESCU, C.F.; FALK, A.; GLIMELIUS, K. Application of AFLPs to characterize somaclonal variation in anther-derived grapevines. Vitis, Siebeldingen, v.41, n.4, p.177-182, 2002.

REISCH, B.I.; PRATT, C. Grapes. In: JANICK, J.; MOORE, J.N. (Ed.). Fruit breeding: vine and small fruits. New York: John Wiley, 1996. v.2, p.297-369.

ROHLF, F. J. NTSYSpc: numerical taxonomy and multivariate analyses system. Version 2.0. New York: Exeter Publications, 1997.

SCOTT, K.D.; ABLETT, E.M.; LEE, L.S.; HENRY, R.J. AFLP markers distinguishing an early mutant of Flame Seedless grape. Euphytica, Wageningen, v.113, n.3, p.245-249, 2000.

SENSI, E.; VIGNANI, R.; ROHDE, W.; BIRICOLTI, S. Characterization of genetic biodiversity with Vitis vinifera L. Sangiovese and Colorino genotypes by AFLP and ISTR DNA marker technology. Vitis, Siebeldingen, v.35, n.4, p.183-188, 1996.

STAUB, J.E.; SERQUEN, F.C.; GUPTA, M. Genetic markers, map construction, and their application in plant breeding. HortScience, Alexandria, v.31, n.5, p.729-741, 1996.

VOS, P.; HOGERS, R.; BLEEKER, M.; REIJANS, M.; van de LEE, T.; HORNES, M.; FRIJTERS, A.; POT, J.; PELEMAN, J.; KUIPER, M.; ZABEAU, M. AFLP: a new technique for DNA fingerprinting. Nucleic Acids Research, London, v.23, n.21, p.4.407-4.414, 1995. 